\title{
DIREITOS HUMANOS, FRATERNIDADE E A PANDEMIA DA COVID-19: POSSIBLIDADES E LIMITES DAS MODALIDADES DE TELETRABALHO EM HOME-OFFICE E COWORKING
}

\author{
Roseana Maria Alencar de Araújo ${ }^{l}$ \\ Vívian De Gann dos Santos ${ }^{2}$ \\ DOI: https://doi.org/10.47306/978-65-88213-03-2.410-422
}

Sumário: 1 Introdução; 2 Direitos Humanos, Fraternidade e a Pandemia da Covid-19; 3 Pandemia, Teletrabalho e a Fraternidade; 4 Considerações Finais; Referências.

\section{Introdução}

O presente artigo pretende, a partir do conceito de Direitos Humanos situados historicamente, apresentar reflexões sobre a necessária adesão à categoria Fraternidade no enfrentamento dos desafios que se impõem a todos e todas no contexto da pandemia da COVID 19, especialmente aos trabalhadores que passaram a prestar seus serviços mediante ferramentas de teletrabalho.

Na contemporaneidade, a humanidade, dado o caráter pandêmico, foi chamada a responder a novas demandas, sequer imaginadas, decorrentes das recomendações de isolamento/distanciamento, que atingiu as mais diversas esferas do convívio social. As pessoas atônitas, aflitas, cansadas com as novas rotinas e frustradas em suas expectativas de retorno às condições de vida anteriormente experienciadas, obrigam-se diariamente a enfrentar diferentes e desafiadoras realidades, diante da atual impotência humana de se conter a pandemia de maneira eficaz.

As projeções mais otimistas apontam para uma vacina que prevenirá a COVID-19 ao final de 2020. Métodos de tratamento e de cura da doença ainda não são reconhecidos pela comunidade científica, de forma segura.

Neste contexto foram impactadas diversas atividades, desde a simples ida ao supermercado, à farmácia, o consumo e o lazer, até as relações de trabalho. Ainda que o

\footnotetext{
${ }^{1}$ Doutora em Ciência Jurídica pela Universidade do Vale do Itajaí - UNIVALI e pela Università degli Studi di Perugia - UNIPG. Professora da Universidade do Vale do Itajaí - UNIVALI. E-mail: ralencar09@hotmail.com. ${ }^{2}$ Doutoranda junto ao Programa de Pós-Graduação em Direito da Universidade Federal de Santa Catarina - UFSC, sob orientação da Profa. Dra. Josiane Rose Petry Veronese. Professora da Universidade do Vale do Itajaí UNIVALI. Advogada. E-mail: vivian@degann.com.br.
} 
teletrabalho fosse uma modalidade que já alcançava uma relativa adesão de empresas e empregados no mundo, a partir da pandemia ela se notabilizou e se tornou uma alternativa viável para a manutenção de parte da empregabilidade e da prestação dos serviços nas esferas públicas e privadas.

Se por um lado esta realidade trouxe uma segurança social para um contingente expressivo de trabalhadores, os quais não ingressaram na situação de desemprego decorrente dos efeitos da pandemia, por outro exigiu conhecimentos, habilidades e competências, de forma imediata, suscitando uma série de problemas de adequação às novas tecnologias e à perspectiva remota do exercício profissional. Novas rotinas, metas, novos horários, bem como a sobrecarga causada pela sobreposição dos trabalhos domésticos e da atividade laboral parecem trazer uma série de comprometimentos relativos à saúde e ao bem-estar dos que se mantiveram no mercado em tais condições.

Assim, considerada a hipótese de que o teletrabalho é um cenário que possivelmente vai perdurar, se busca, com o presente artigo, um enfoque panorâmico das possiblidades e limites do home-office e do coworking, aliado a imprescindível observância das normas protetivas dos trabalhadores vigentes nos Ordenamentos Jurídicos Nacional e Internacional, bem como a vivência de relações fraternas neste âmbito da convivência humana.

Para tanto, passa-se a tratar dos Direito Humanos e da Fraternidade no contexto da pandemia causada pela COVID-19, para ingressar-se no debate de sua aplicabilidade a dois formatos de teletrabalho comumente buscados na atualidade para solucionar os empecilhos ligados ao trabalho presencial: home office e o coworking.

\section{Direitos humanos, fraternidade e a pandemia da covid-19}

No presente trabalho, para demonstrar a relevância da categoria Fraternidade no contexto da Pandemia da COVID-19 (especificamente quanto às demandas emergentes em face do trabalho remoto, nas modalidades de home-office e coworking), parte-se da concepção de Perez Luño relativa aos Direitos Humanos, concebidos tal como uma agregação de faculdades e instituições, as quais, “[...] em cada momento histórico, concretizam as exigências de dignidade, liberdade e igualdade humana, as quais devem ser reconhecidas pelos ordenamentos jurídicos, nos planos nacional e internacional” (LUÑO, 1988).

Destaca-se a historicidade desse conjunto de prerrogativas inerentes a qualquer pessoa ou a qualquer grupo humano, considerados em uma perspectiva espaço-temporal. Assim, o 
núcleo axiológico apontado pelo autor, composto pela dignidade, liberdade e pela igualdade humana, urge acrescer a Fraternidade por razões que serão explicitadas posteriormente.

Não se pretende aqui descrever minunciosamente a evolução dos Direitos Humanos, consideradas as lutas, as conquistas, bem como os retrocessos da humanidade, mas evidenciar dois momentos históricos, quais sejam: a Revolução Francesa de 1789 e o Pós Segunda Guerra Mundial, nos quais se estabeleceram as bases axiológicas a serem perseguidas relativamente à convivência humana, em uma proposta universal.

A ruptura política do Antigo Regime por meio de um processo revolucionário na França, em 1789, trouxe um protagonismo tanto para a classe burguesa, como para o povo. Ambos os atores se transmutaram de súditos em cidadãos, bem como se notabilizou, como um dos seus lemas, os valores da Liberdade, da Igualdade e da Fraternidade (EMABAIXADA DA FRANÇA).

Na mesma perspectiva, o término da Segunda Guerra Mundial e os horrores cometidos pelos envolvidos no conflito, suscitou, como pauta emergencial, a necessidade de um comprometimento das nações com vistas a impedir que as graves violações dos Direitos Humanos pudessem se repetir no futuro. Desta forma, surgiu o documento paradigmático denominado Declaração Universal dos Direitos Humanos de 1948, proclamada pela Assembleia Geral das Nações Unidas, em 10 de dezembro de 1948, por meio da Resolução 217 A (III) (ONU, 1948).

Cumpre ressaltar que a referida Declaração, em seu artigo 1. ${ }^{\circ}$, consagrou três valores essenciais, como se demonstra a seguir: "todos os seres humanos nascem livres e iguais em dignidade e direitos. São dotados de razão e consciência e devem agir em relação uns aos outros com espírito de fraternidade" (ONU, 1948).

Sobre os valores da Liberdade e da Igualdade muito já se produziu quanto à influência que exerceram e exercem nos Ordenamentos Jurídicos, nos âmbitos Internacional e dos Estados Nacionais. Convencionou-se, farta produção acadêmica, a tratar o conjunto de direitos relativos a essas duas categorias em dimensões - uma primeira dimensão estaria relacionada à liberdade e a segunda à igualdade. Esse avanço civilizatório foi incorporado especialmente nas Constituições dos Estados Nacionais e, por conseguinte, na própria experiência humana no sentido de assegurar a cada pessoa sua realização como ser livre e consciente do papel do Estado em relação à consecução de seu acesso aos bens e às oportunidades (BAGGIO, 2009, p. 01).

Por outro lado, o enfoque deste artigo pressupõe a exploração, com um maior aprofundamento, do Princípio esquecido, como se denota pelo texto de Baggio: "enquanto, porém os princípios-deveres da igualdade e da liberdade tiveram um desenvolvimento, a partir 
de 1798 e transformaram-se em categorias políticas [...] entrando como princípios nas Constituições de vários Estados, a mesma sorte não coube à fraternidade" (BAGGIO, 2008).

A Fraternidade pressupõe a noção prévia de estar em consonância com o outro, de poder sentir a dor do outro e de se irmanar quanto as suas possiblidades e limites, como parceiro de existência. A ideia da Fraternidade não é nova, mas toma consistência como uma alternativa de uma concreta realização da liberdade e da igualdade sobre outro parâmetro: o da condição humana que nos une como seres sensíveis e tolerantes uns com os outros quanto às diversidades econômicas, sociais, culturais, étnica-raciais, de gênero, dentre outras perspectivas.

Neste sentido, Lafer ao comentar o art. 1. ${ }^{\circ}$ da Declaração Universal dos Direitos Humanos, ressalta a origem cristã da ideia da Fraternidade e a sua secularização, como ainda a relevância desse valor para o pacifismo, como uma condição a ser concretizada para o bemestar de todos os povos:

$\mathrm{O}$ artigo $1 .^{\circ}$ retoma não apenas a formulação do valor da igualdade e da liberdade da Revolução Francesa, mas também o da fraternidade, que é a expressão da secularização do conceito cristão de filhos de Deus. [...]. Neste sentido, o espírito da fraternidade consagrado no art. $1 .^{\circ}$ contesta a relação política concebida como uma relação amigo/inimigo e é uma instigação ao 'desenvolvimento das relações amistosas entre as nações' (LAFER, 2008, p. 33).

Ilustra-se que no caso do Ordenamento Jurídico brasileiro, notadamente da Constituição da República Federativa do Brasil de 1988, a Fraternidade está mencionada no Preâmbulo - e a Solidariedade, também tem lugar em alguns dos seus 250 artigos, a exemplo do inciso I, do art. 3. ${ }^{\circ}$ que trata dos objetivos da República Federativa do Brasil, qual seja "[...] a construção de uma sociedade livre, justa e solidária” (BRASIL, 1988).

Distingue-se, no âmbito deste artigo, o conceito da categoria Fraternidade em relação à Solidariedade. A primeira se encontra em outro patamar de sensibilidade humana. Ao passo que a Solidariedade consiste em um compromisso de se importar com o outro, mas não pressupõe uma horizontalidade das relações humanas. Neste sentido, esclarece Baggio:

\footnotetext{
A Solidariedade - como muitas vezes foi historicamente realizada - viabiliza que se faça o bem ao outro mesmo mantendo uma posição de força, uma relação 'vertical' que vai do forte ao fraco; a fraternidade, no entanto, pressupõe o relacionamento horizontal, a divisão dos bens e dos poderes [...] (BAGGIO, 2008, p. 23).
}

A opção do presente artigo recai para a utilização da categoria Fraternidade, no sentido da comunhão entre os seres, tanto com aquele que se partilha o cotidiano, bem como com o Outro desconhecido, que integra a família humana. Neste caminho, que implica na tolerância e na empatia, nunca se está sozinho. Mesmo as adversidades que se impõem devem ser superadas a partir do respeito mútuo, da composição dos conflitos e do reconhecimento que enquanto o 
Outro não for reconhecido em sua dignidade, não há como se conquistar a Liberdade e a Igualdade em sua plenitude.

Os diversos desafios que o mundo contemporâneo engendra quanto à realização de uma justiça global só poderão ser superados a partir do fortalecimento do humanismo, da condição de importar-se com o Outro, e de um compromisso inarredável com o estabelecimento de relações fraternas em todas as esferas da convivência. Não é uma tarefa fácil, consideradas as premissas do neoliberalismo econômico, do consumismo, do estímulo à competitividade, do individualismo, do etnocentrismo e do patriarcado.

No que se refere aos caminhos a serem trilhados, reproduz-se o posicionamento de Veronese e Fonseca, a partir do qual, faz-se:

[...] necessária a construção de um novo paradigma, baseado numa visão ética da
história: no acreditar no ser humano, na dignidade da pessoa humana, na edificação de
novos valores, através do qual, não cancelando a pessoa, em seu caráter individual,
conheça-se o alcance da fraternidade, da participação, do comunitário e, também não
negando o fato de que somos diferentes, não nos conformamos, no sentido de que não
compactuamos com uma sociedade cuja ordem econômico-político-social seja pautada
por situações de extremas, discrepantes desigualdades e contradições; uma sociedade
que cultue o ódio e o seu discurso precisa ser obstada $(2019$, p. 25$)$.

Com base nestas observações, fica evidenciada a necessidade da apreensão do verdadeiro sentido da Fraternidade no contexto da crise sanitária que o mundo atravessa no ano de 2020, causada pelo novo Coronavírus, e a sua correspondente patologia: a Covid-19.

Cumpre destacar alguns aspectos relativos à doença e as suas manifestações. Os Coronavírus causam infecções respiratórias, tendo sido isolados pela primeira vez em 1937. A denominação se deu por conta de sua aparência microscópica semelhante a uma coroa. Mas o novo agente, cujo nome oficial é Sars Cov 2 foi detectado na China, na cidade de Wuhan, local que se tornou rapidamente o epicentro da sua propagação. Descoberto em 31 de dezembro de 2019, já em 11 de março de 2020, a velocidade intensa de sua disseminação fez com que a Organização Mundial de Saúde elevasse o estado da contaminação à pandemia, devido a sua abrangência em todo o planeta (OPAS/OMS, 2020; BRASIL, 2020).

Em 28 de junho de 2020, segundo a Universidade John Hopkins, foram contabilizados mais de 10 milhões de pessoas infectadas e mais de 500 mil mortes em todo mundo (GLOBO/G1, 2020). Na mesma data o Brasil apresentava os seguintes números: 1.344.143 pessoas contaminadas e 57.622 óbitos registrados (CORONAVÍRUS BRASIL, 2020).

A crise sanitária causada por esta nova doença e suas consequências nas diversas dimensões da existência, surpreende a todos e todas, em nível global. Neste sentido enfoca-se, especialmente, as necessárias e vertiginosas adaptações no mundo do trabalho em decorrência da necessidade de isolamento/distanciamento social, em um cenário no qual se projeta a 
continuidade de determinadas relações de produção em ambiente remoto, até que haja a identificação de meios preventivos e de tratamento eficazes contra a COVID-19.

Há que se salientar, também, que essas novas configurações das relações de trabalho possivelmente perdurarão após à descoberta de vacinas e da cura da doença, integrando às prováveis mudanças estruturais do contexto social pós-pandemia, contexto esse recebeu a denominação de “o novo normal”. Sobre esta nova expressão, reproduz-se parte de entrevista da Dra. Maria Aparecida Rhein Schirato, a qual conta com vasta experiência em Ética e Comportamento Organizacional:

O novo normal, na verdade, seria a proposta de um novo padrão que possa garantir
nossa sobrevivência. [...] Vamos ter que andar com máscara, mais contidos, menos
expansivos, como se estivéssemos no frio. [...] O que tem de comum nesses debates é a
busca da segurança. Estamos na possibilidade de uma segunda onda universal de
contágio, com a criação de uma vacina que, no melhor dos cenários, pode acontecer até
o final do ano. Temos, ainda, a possibilidade de mutação do vírus, que faria com que
essa vacina pensada agora não dessa conta de uma possível volta do vírus, já com
alguma composição diferente. Temos ainda algum tempo, não há como prever
exatamente quanto, de termos que apostar em um novo modelo de vida. E também
descobrimos algumas vantagens desse novo modelo. Temos alternativa de home office,
atualmente, e estamos vendo que funciona - descobrimos que é possível e econômico.
Percebemos que não precisamos percorrer grandes distâncias ou enfrentar chuvas
torrenciais para fazermos reuniões. Continuamos em casa e fazemos nossa própria
comida. O trânsito é menor e temos menos poluição. (INSPER, 2020).

De se pontuar que neste período atípico não se acumulou exclusivamente as vantagens elencadas pela autora. No âmbito laboral, a pandemia da COVID-19 trouxe a realidade do teletrabalho para um contingente expressivo de empregados que, instantaneamente, se obrigaram a manter sua produtividade em novos espaços e rotinas de trabalho. É o que se passa a tratar no tópico seguinte ao traçar as possibilidade e limites de duas formas de teletrabalho comumente empregadas no país: o home office e o coworking - o que se fará, sob o olhar da Fraternidade.

\section{Pandemia, teletrabalho e a fraternidade}

Na conjuntura laboral em meio a pandemia, o trabalho em home office passou a ser uma das principais alternativas de empregados e de empregadores por todo o Brasil, especialmente diante das práticas de isolamento/distanciamento social impostas à população, porém nem todos se adaptam facilmente.

A primeira problemática reside na adequação do espaço da residência do empregado para atender à necessidade de insumos inerentes a sua prestação de serviços (desde o mobiliário, até a internet). A legislação nacional, pela redação do art. 75-D da CLT, permite negociações 
entre empregados e empregadores quanto à responsabilidade por tais custos - ou seja, é possível alocar valores sob a responsabilidade do empregado, ou se fixar quantias pagas em antecipação, ou por reembolso, pelo empregador para cobrir as despesas desta natureza (BRASIL, 1943).

Deve-se ponderar, entretanto, que a Organização Internacional do Trabalho - OIT, firmou posicionamento no sentido de que gastos decorrentes dos meios de conexão com o trabalho, como também daqueles originados no uso de energia e água, comunicação e manutenção de equipamentos e maquinários, entre outros indispensáveis ao desenvolvimento do trabalho, devem ser reembolsados pelo empregador (Convenção n. 177 e Recomendação n. 184, da OIT) (BRASIL, 1943). Desta forma, é prudente ao empregador arcar com as despesas aqui referidas.

Mas, de se questionar por que a negociação quanto aos encargos relativos às ferramentas de trabalho seria uma dificuldade. Bem, todos os equipamentos empregados no trabalho em home office (mediante o uso de computadores e internet, por consequência), constituem insumos da atividade produtiva que devem obedecer às regras de Segurança e Medicina do Trabalho. Esses insumos precisam atender às indicações de ergonomia, a fim de que se evite o adoecimento de trabalhadores, a exemplo do desenvolvimento de doenças crônicas, como lesões por esforço repetitivo. Assim, apenas antecipar ou reembolsar aos empregados valores gastos com a aquisição de mesas, cadeiras, entre outros apetrechos, não garante o cumprimento da referida obrigação, muito menos respeita a dignidade do trabalhador, especialmente se abarcar-se a Fraternidade nesta análise.

Aliás, o dever do empregador ultrapassa o fornecimento adequado de ferramentas de trabalho. Neste sentido, também se inclui a obrigação de fiscalizar o uso adequado pelo empregado, inclusive na hipótese de teletrabalho na modalidade home office. Esta tarefa revelase dificultosa, na medida em que o espaço da residência do empregado é resguardado pelo direito à intimidade e à inviolabilidade de domicílio, o que impõe limitação à presença e à fiscalização direta do empregador. Contudo, reforça-se que, conforme indica a CLT (arts. 157 e 158), cabe a todo empregador executar as normas de Segurança e Medicina do Trabalho, bem como, instruir seus empregados acerca das precauções necessárias a serem tomadas para evitar acidentes do trabalho ou doenças ocupacionais, de forma a resguardar-se a sua saúde (BRASIL, 1943).

A não observância desses fatores, cumulada com o adoecimento do empregado, pode gerar a responsabilidade do empregador em indenizar o trabalhador por eventual perda da capacidade de trabalho (ainda que parcial), bem como, acarretar afastamento previdenciário do 
empregado por auxílio doença (acidentário) - situação que origina ao empregado o direito à garantia provisória de emprego de 12 meses após o seu retorno às atividades profissionais.

De toda forma, mesmo que o empregador detenha meios para garantir o atendimento de todos os requisitos legais mencionados, com uso de tecnologias por exemplo, é de se considerar que nem todo empregado terá em seu ambiente doméstico o espaço adequado para exercer suas atividades de forma produtiva. A coabitação com diversos familiares, o pouco espaço físico das residenciais atuais, as necessidades de atendimento aos filhos e outros dependentes, podem comprometer o desenvolvimento do trabalho.

Outra dificuldade apresentada pela sistemática do home office é a adaptação do empregado ao distanciamento do convívio social de forma abrupta e massiva. Em que pese ser viável a mudança do trabalho presencial para o teletrabalho, e a sua reversibilidade, conforme as disposições dos parágrafos primeiro e segundo do art. 75-C, da CLT, como ainda a participação do teletrabalhador em atividades esporádicas nas dependências do empregador (parágrafo único do art. 75-B, da CLT), o afastamento do empregado do convívio social é sentido em análises recentes sobre a implementação de teletrabalho. Rocha e Amador compreendem que:

[...] alguns teletrabalhadores relatam o excesso de trabalho como resultado da adoção da flexibilização de tempo e espaço. Isso pode ocorrer tanto pela adoção de metas de produtividade maiores para o trabalho remoto do que as que seriam cobradas na jornada tradicional como pelo transbordamento do trabalho presencial (ou sobretrabalho) realizado em domicílio. Demonstra-se que os dispositivos para tornar o tempo elástico podem ser utilizados como formas de intensificar o trabalho para compensar a redução das equipes, uma estratégia frequente em empresas multinacionais.

$[\ldots]$

A produção típica do trabalhador adequado ao teletrabalho indica uma tendência à superindividualização do trabalho - que pode acarretar consequências primeiro ao trabalhador individualmente, com isolamento social, profissional e político. Pode levar, ainda mais amplamente, à transformação cultural da sociedade, com vulnerabilidade geral das relações de trabalho, perda da dimensão coletiva do trabalho e incremento dos processos de individualização no campo social (ROCHA; AMADOR, 2018).

Nesse sentido, embora a flexibilidade de horários de trabalho seja comumente apontada como um benefício do teletrabalho em home office, tanto para o empregado quanto para o empregador, tal possibilidade viabiliza a quebra da desconexão entre vida pessoal e vida profissional. Uma das dificuldades mais relatadas por home workers é exatamente o aumento significativo da sua vinculação ao trabalho, com a consequente perda do ócio - que envolve os momentos de descanso e lazer, necessários à manutenção da saúde mental.

Por tais circunstâncias, verifica-se a elevação do risco de adoecimento mental dos empregados em teletrabalho, na modalidade home office - mais uma hipótese que pode 
ocasionar afastamentos (previdenciários) do trabalho por longo período, em prejuízo do trabalhador e do empregador.

Em entrevista recente sobre a temática, a psicóloga e tecnologista da Fundacentro, Laura Nogueira, destacou que:

[...] neste momento, uma das características mais preocupantes quando se fala de saúde mental é a questão do distanciamento social, a brusca quebra da rotina, e para muitos trabalhadores a possibilidade de queda da renda. Fatores que podem levar ao mal-estar psicológico', e complementou indicando que 'o home office permite uma flexibilidade de horário que se não for bem gerenciada pode ocasionar sobrecarga de trabalho. Um local mais reservado na casa e o estabelecimento de rotinas de trabalho tornam-se essenciais para estabelecer uma fronteira entre o trabalho e a vida pessoal. Assim como o estabelecimento de um tempo para o descanso e o desenvolvimento de atividades de lazer' (NOGUEIRA, 2020).

Por outro lado, o abrandamento das restrições do isolamento social no país, com a reabertura de alguns setores industriais e comerciais, permitiu a retomada de outro modelo de teletrabalho: o coworking. Ainda que para utilizá-lo atualmente sejam indispensáveis certas precauções (uso de máscara, distanciamento entre mesas de trabalho, etc), hoje é perfeitamente possível a adesão a esta modalidade de teletrabalho.

Na hipótese de utilização pelo empregador de coworkings como espaços de teletrabalho, as problemáticas do home office antes apresentadas parecem mais atenuadas. Primeiro, porque as questões relacionadas à Segurança e Medicina do Trabalho são mais facilmente atendidas nos espaços de coworking, as quais podem ser direta e irrestritamente fiscalizadas e ajustadas pelos empregadores. Segundo, a estruturação dos coworkings, por sua natureza, facilita a integração de seus usuários, diante dos compartilhamentos de espaços de trabalho e de descanso disponibilizados, o que permite o abrandamento das condições negativas que decorrem da ruptura das rotinas de trabalho presencial, experimentada pelos home workers com maior frequência.

Ainda, em razão dos coworkings vincularem a prestação de serviços do empregado à espaço diverso de sua residência, ou seja, de promoverem uma divisão real entre o trabalho e a vida pessoal, há um estímulo à desconexão efetiva do empregado, fator que agrega estímulo ao descanso e, consequentemente, às atividades afetas aos cuidados com a higidez mental.

Provavelmente o home office e coworkings seguirão amplamente procurados como soluções às limitações de mobilidade indicadas ao enfrentamento da pandemia atual, que devem estender seus reflexos em um futuro próximo. Nesse contexto, não se questiona a necessidade da reinvenção do modo de vida e trabalho, que demanda a resiliência de empregados e de empregadores. Entretanto, a readequação, especialmente a profissional, pode dar-se dentro de uma diversidade de formatações de teletrabalho disponíveis, que podem ser adequadas à cultura 
e à realidade de cada empreendimento, com vistas não só a conservação das atividades empresariais, mas também à saúde física e mental dos empregados envolvidos - de modo a manter as rotinas laborais estruturadas entre empregados e empregadores dentro dos primados da Fraternidade.

Nesta perspectiva se resgata a importância do papel do Estado, em conjunto com empregadores e empregados, e da própria sociedade, no sentido de viabilizar condições de trabalho dignas, garantindo a eficácia das normas de Medicina e Segurança do Trabalho vigentes, bem como atualizando a legislação para esse novo tempo vivenciado. A crise é global e impacta todos os setores da vida humana, com destaque para o mercado de trabalho e para as condições biopsicossociais de cada habitante do planeta. Desta forma, conforme Oliveira e Veronese:

[...] torna-se evidente que ante os mais variados conflitos que flagelam a nossa contemporaneidade, a vivência da fraternidade é a que tornará possível a transformação das estruturas sociais, contribuirá para a formação de uma nova cultura que coloque em relevo a riqueza das relações humanas, de modo que possamos compreender que neste século XXI o grande bem a ser agregado aos demais se trata do bem relacional, o qual pode ser apreendido como um meio capaz de reavivar na humanidade a completude de sua existência (OLIVEIRA; VERONESE, 2011, p. 21).

A perspectiva da precarização das condições de trabalho (e de teletrabalho), em virtude da retração global da economia, com cenários agravados nos países em desenvolvimento como o Brasil, terá que ser enfrentada com firmeza e determinação, mas acima de tudo com sensibilidade e empatia. Os desafios se impõem, em sucessivas e desgastantes demandas diárias, especialmente quanto a conciliação do trabalho doméstico com as atividades laborais. As fronteiras entre o espaço privado e o ambiente laboral se flexibilizaram e os conflitos advindos destas novas circunstâncias não se limitam a esfera privada, e nem às competências dos Estados nacionais.

Assim, a Fraternidade se impõe como condição basilar para que sejam respeitadas as possiblidades e limites de cada trabalhador nos processos de adaptação laboral exigidos pelas atuais circunstâncias sanitárias, bem como ao que se convencionou denominar de "novo normal” pós-pandemia.

\section{Considerações finais}

A Pandemia da COVID-19 impacta a todos os seres humanos, nas mais diversas dimensões da convivência e exige uma capacidade de adaptação sem precedentes na contemporaneidade. Esses desafios se impõem desde as mais singelas atividades do cotidiano 
às novas configurações das relações individuais e coletivas. A permanência na casa, em tempos de isolamento/distanciamento social, o acesso restrito às atividades de lazer causados pelo confinamento, a necessidade de divisão dos espaços e das tarefas concernentes as esferas públicas e privadas causam efeitos nas condições de saúde e na qualidade de vida das pessoas, ainda não mensurados.

A cada dia noticia-se o incremento dos casos e das mortes. Os países nos quais foram superados os picos de contágio, vêm ora flexibilizando, ora restringindo o convívio social, à espreita de uma nova onda de contaminação. Por outro lado, de forma positiva, crescem os números de casos recuperados.

Neste cenário de incertezas, as mudanças seguem e no âmbito laboral se evidencia um protagonismo do teletrabalho em suas diversas modalidades. Desta forma procurou-se tecer considerações a respeito das atividades laborais desenvolvidas em home-office e em coworking, à luz das normas protetivas nacionais e internacionais, a fim de evidenciar uma tendência ao reconhecimento do coworking como uma alternativa mais adequada à concretização da saúde e do bem-estar do trabalhador. Mas as reflexões aqui trazidas, longe de esgotar o tema, revelam, com os dados preliminares dessas novas condições de trabalho, apenas pontos de partida para o aprofundamento dos debates.

$\mathrm{Na}$ mesma perspectiva, apontou-se para a relevância da categoria Fraternidade, nas discussões e nas vivências deste novo período da humanidade, o qual se revela desafiador e inseguro, inclusive para as relações laborais. A pandemia da COVID-19 colocou em evidência a fragilidade e a incapacidade humana de ter o controle sobre a vida e a morte. Ninguém sairá igual desta experiência planetária. E é neste sentido que se conclama a Fraternidade, para que de forma empática, ética e responsável se possa encontrar soluções individuais e coletivas com vistas ao alcance e à preservação das condições dignas para a toda a população global, em especial aos trabalhadores que seguem suas atividades nos diversos formatos de teletrabalho.

\section{REFERÊNCIAS}

BAGGIO, Antonio Maria (Org). O princípio esquecido. São Paulo: Cidade Nova, 2008.

BAGGIO, Antonio Maria (Org). O Princípio esquecido 2: exigências, recursos e definições da fraternidade. Org. São Paulo: Cidade Nova, 2009.

BRASIL. Constituição da República Federativa do Brasil de 1988. Disponível em:. http://www.planalto.gov.br/ccivil_03/constituicao/constituicao.htm. Acesso em 20 mai 2020. 
BRASIL. Decreto Lei n. 5.425, de $1^{\circ}$ de maio de 1943. Aprova a Consolidação das Leis do Trabalho. Disponível em: http://www.planalto.gov.br/ccivil_03/decreto-lei/del5452.htm. Acesso em: 28 jun. 2020.

BRASIL. Ministério Da Saúde. Sobre a doença. Disponível em:

https://coronavirus.saude.gov.br/sobre-a-doenca. Acesso em 28 jun. 2020.

CORONAVÍRUS BRASIL. Painel coronavírus. Disponível em: https://covid.saude.gov.br/. Acesso em 28 jun. 2020.

EMBAIXADA DA FRANÇA. Liberdade, igualdade e fraternidade. Disponível em: https://br.ambafrance.org/-Portugais-. Acesso em 30 mai. 2020.

GLOBO/G1. Mortes por Covid-19 passam de 500 mil no mundo, diz universidade Johns Hopkins. Disponível em:

https://g1.globo.com/bemestar/coronavirus/noticia/2020/06/28/mortes-por-covid-19-passamde-500-mil-no-mundo-diz-universidade-johns-hopkins.ghtml. Acesso em 28 jun 2020.

INSPER. NOTÍCIAS. CHIRATO, Maria Aparecida Rhein Schirato. Novo normal: entenda melhor esse conceito e seu impacto em nossas vidas. Disponível em:

https://www.insper.edu.br/noticias/novo-normal-conceito/. Acesso em 02 jun. 2020.

LAFER, Celso. A declaração universal dos direitos humanos - sua relevância para a afirmação da tolerância e do pluralismo. In: MARCÍLIO, Maria Luiza (org.). A declaração universal dos direitos humanos. Sessenta anos: sonhos e realidades. São Paulo: EDUSP, 2008.

NOGUEIRA, Laura. Home office e distanciamento social requerem cuidados com a saúde mental. Fundacentro. Disponível em: http://www.fundacentro.gov.br/noticias/detalhe-danoticia/2020/4/home-office-e-isolamento-social-requerem-cuidados-com-a-saude-mental. Acesso em: 26 mai. 2020.

OIT - Organização Internacional do Trabalho. Convenções não ratificadas. Disponível em: https://www.ilo.org/brasilia/convencoes/WCMS_242947/lang--pt/index.htm. Acesso em: 29 jun. 2020.

OLIVEIRA, Olga Maria Aguiar de; VERONESE, Josiane Rose Petry (Org.). Direitos na pós modernidade: a fraternidade em questão. Florianópolis: Fundação Boiteux, 2011.

ONU - Organização Das Nações Unidas. Declaração Universal de Direitos Humanos.

Disponível em: https://nacoesunidas.org/wp-content/uploads/2018/10/DUDH.pdf. Acesso em 15 mai. 2020.

OPAS/OMS BRASIL. Folha informativa - COVID-19. Disponível em: https://www.paho.org/bra/index.php?option=com_content\&view=article\&id=6101:covid19\&I temid=875. Acesso em 28 jun. 2020.

PEREZ LUÑO, Antônio Henrique. Derechos Humanos, estado de direito e constituición. 4.ed. Madrid: Tecnos, 1988. 
ROCHA, Cháris Telles Martins da; AMADOR, Fernanda Spanier Amador. O teletrabalho: conceituação e questões para análise. Cadernos EBAPE.BR, v. 16, nº 1, Rio de Janeiro, Jan./Mar. 2018. Disponível em: http://www.scielo.br/pdf/cebape/v16n1/1679-3951-cebape16-01-152.pdf. Acesso em: 25 mai. 2020.

VERONESE, Josiane Rose Petry; FONSECA, Reinaldo Soares da. (Org.) Literatura, direito e fraternidade. Florianópolis: EMAIS, 2019. 